\title{
"Reproponer" la función de la propiedad privada
}

\author{
Gustavo Roque Irrazábal ${ }^{\cdot}$ \\ Facultad de Teología \\ Pontificia Universidad Católica Argentina \\ girrazabal@gmail.com \\ Recibido 08.11. 2020/11.02.2021 \\ DOI: https://doi.org/10.46553/teo.58.134.2021.p43-74
}

\section{RESUMEN}

El presente trabajo tiene por fin «reproponer» la función de la propiedad privada, a través de tres autores que enfatizan su dimensión social considerándola -a partir de su subordinación al destino universal de los bienes- como un derecho derivado e instrumental. Me propongo criticar esta visión, tanto por su fundamento y conclusiones como por su falta de referencia a una clara teoría de las facultades y límites del Estado, por lo cual aquella se presta a manipulaciones ideológicas y crea peligros para la libertad individual, la paz social y el desarrollo económico. Una comprensión actualizada del destino universal de los bienes en el contexto de la economía moderna puede iluminar el modo más eficiente de ejercitar la responsabilidad social inherente a este derecho.

Palabras clave: Propiedad privada; Destino universal de los bienes; Hipoteca social; Derecho natural

\section{The Function of Private Property revisited}

\section{ABstract}

In this work I revisit the function of the private property, through three authors who emphasize its social dimension, considering its subordination to the universal destiny of earthly goods as a sign of its derivative and instrumental character. I will criticize this vision in its foundation and conclusions, as well as for the lack of a clear reference to the faculties and limits of the State. These weaknesses may derive in ideological manipulation, and may pose risks to individual liberty, social peace and economic development. An updated comprehension of the universal destination of created goods leads to more efficient ways of exercising the social responsibility inherent to this right. Keywords: Private Property; Universal Destiny of Created Goods; Social Mortgage; Natural Right

- El autor es profesor de Teología Moral en la Facultad de Teología de la Pontificia Universidad Católica Argentina. 
En su reciente encíclica Fratelli tutti (FT) -sobre todo en nn. 118-120 - el Papa señala la necesidad de «reproponer» la función social de la propiedad, considerando esta última como un derecho "natural secundario y derivado» respecto al derecho "natural, originario y prioritario» del uso común de los bienes creados (FT 120; cf. CDS 172). Podría sorprender el hecho de que la propiedad privada sea abordada exclusivamente desde su límite, y no desde su función positiva para la vida personal y social (CDS 176). Sin embargo, esta visión refleja una vigorosa y extendida corriente dentro de la actual Doctrina Social de la Iglesia (DSI).

Como observaba recientemente el especialista M. Schlag, entre los estudiosos de la DSI, tanto en Estados Unidos como en Europa, prevalece una orientación afín a la teología de la liberación. ${ }^{1}$ Incluso, de un modo más amplio, se puede afirmar que el mainstream en esta disciplina se muestra hoy en una marcada sintonía con las posiciones de los liberals americanos o de los socialdemócratas europeos. Es cierto que su interpretación del magisterio social y de la tradición de la Iglesia puede reflejar mejor algunas de sus vertientes o llevar a sus últimas consecuencias lógicas algunos de sus argumentos, pero también presenta debilidades que dejan espacio para la reflexión crítica.

Este trabajo tiene por objeto «reproponer» la función integral de la propiedad privada, tanto la llamada «social» como la personal. ${ }^{2}$ Para ello expondré ante todo la visión que centra el sentido de este derecho en su función social, a través de algunos destacados autores de esta orientación. A continuación, buscaré mostrar que dicha visión puede ser contestada desde la misma tradición de la Iglesia, y que en importantes aspectos no guarda una clara consistencia con los principios de la DSI. Dicho en positivo, es posible pensar la

1 Cf. Martin Schlag Schreier, Cómo poner a dieta al caníbal: Ética para salir de la crisis económica (Madrid: Rialp, Edición Kindle, 2015), cap. 2.1. Siglas: ST, Suma teológica; CDS: Compendio de la Doctrina Social de la Iglesia; RN: Rerum novarum; QA: Quadragesimo anno; MM: Mater et Magistra; PT: Pacem in terris; PP: Populorum progressio; OA: Octogesima adveniens; LE: Laborem exercens; SRS: Sollicitudo rei socialis; CA: Centesimus annus; FT: Fratelli tutti.

2 Adelanto que tal clasificación de las funciones de la propiedad privada no está libre de reparos (cf. Infra, 5, in fine) y que las mismas deben entenderse, al menos, de un modo mejor integrado. 
propiedad privada en términos que reflejen mejor la antropología cristiana y la continuidad profunda de la DSI, y que a la vez sean aptos para brindar respuesta a las exigencias actuales de la justicia social. La opción por presentar estos autores separadamente hace inevitable incurrir en algunas repeticiones en temas en los cuales sus pensamientos coinciden, pero también posibilita visualizar matices y diferencias que se perderían si intentáramos fundirlos en una artificial uniformidad.

\section{1. «Catholic Social Teaching», de Charles Curran}

En su obra Catholic Social Teaching, ${ }^{3}$ Charles Curran comienza el tratamiento del tema refiriéndose al magisterio de León XIII en Rerum Novarum (RN). Curran señala la insistencia de este pontífice en afirmar el carácter natural de la propiedad privada y la justicia de su adquisición a través del trabajo. La perspectiva de RN -más adecuada al tradicional trabajo agrícola que al fenómeno nuevo del trabajo industrial- resulta útil para abordar los derechos de los trabajadores, pero a su juicio deja de lado el problema del abuso de la propiedad privada por parte de los dueños y los capitalistas. Y por lo tanto serán sobre todo los límites de este derecho el tema que Curran procurará iluminar con su la reflexión.

\subsection{Propiedad privada y ley natural}

En la opinión de este autor, León XIII -pese a ser un gran promotor del pensamiento tomista en su versión neoescolástica- paradójicamente adoptó una visión de la propiedad privada diversa a la del mismo Santo Tomás. Como prueba de su aseveración, cita dos artículos de la Suma Teológica: II-II, q.66, a.1 y a.2.

3 Charles Curran, Catholic Social Teaching (1891-present). A Historical, Theological and Ethical Analysis (Washington DC: Georgetown University Press, 2002), en adelante, CST. 
- En el primero, el Aquinate se pregunta si es natural para el hombre poseer bienes exteriores, a lo cual responde que, en cuanto a su naturaleza, las cosas están sometidas a la potestad de Dios que las creó, pero en cuanto a su uso, el hombre tiene un dominio natural de las cosas materiales, ya que es capaz de ponerlas al servicio de su propia utilidad en virtud de su razón y su voluntad.

- En el segundo, se pregunta si es lícito para el hombre poseer algo como propio, y responde distinguiendo: en cuanto a su gestión, dicha posesión es lícita, ya que el hombre es más solícito en cuidar lo propio; se favorece el orden en la administración de los bienes; y se fomenta la paz definiendo los derechos de cada uno. En cuanto a su uso, sin embargo, el hombre no debe tener las cosas como propias, sino como comunes.

La conclusión a la que llega Curran es que el primer artículo se refiere al «dominio genérico» que corresponde a los seres humanos de todos los bienes de la tierra para satisfacer sus necesidades, mientras que el segundo justifica la propiedad privada, fundado en los motivos enunciados, aunque subordinándolo a la dimensión común de los bienes exteriores. La mención de la naturaleza racional del hombre (a.1) estaría referida exclusivamente al uso común, mientras que la propiedad privada no se justificaría en base a la naturaleza humana sino a las «condiciones históricas» de la existencia humana en este mundo pecador «que hacen más conveniente su adopción». ${ }^{4}$

Es cierto que la propiedad privada no contradice la ley natural, pero es un «agregado» (superadditur) a la misma, en virtud de una exigencia de la razón (a.2, ad 1). Esto se explica porque la ley natural puede entenderse en dos sentidos: como aquello a lo cual inclina la naturaleza (y en este sentido, S. Isidoro de Sevilla dice que la posesión común es de ley natural); o como aquello que no es contrario a la misma. La propiedad privada puede «agregarse» a la ley natural por ser necesaria en la actual condición pecadora del

4 CST, 176. 
hombre. De hecho, las tres razones aducidas en el cuerpo del a.2 tendrían su origen en la condición pecaminosa del hombre, y carecerían de sentido en el estado de inocencia original.

De esto se sigue, en la opinión de este autor, que para S. Tomás la propiedad privada no sólo está limitada en cuanto a su uso por el destino universal de los bienes, sino también en cuanto al derecho mismo. Prueba de ello sería el caso de la persona en necesidad extrema, que podría tomar lo necesario de otro sin cometer robo (q.67, a.7).

En conclusión, la idea del carácter natural de la propiedad privada sería ajena al verdadero pensamiento tomista, y habría ingresado en el magisterio recién con $\mathrm{RN}$, debido a la formación que recibió León XIII del P. jesuita Luigi Taparelli d'Azeglio, uno de los fundadores del movimiento neoescolástico en el s. XIX.5 Curran ve como más cercana a $S$. Tomás la posición del teólogo americano John A. Ryan (1869-1945), quien enfatiza la instrumentalidad de la propiedad privada, por la cual podría eventualmente ceder ante «formas modificadas de propiedad común». ${ }^{6}$ El magisterio social posterior habría corregido progresivamente aquel sesgo individualista, dejando de lado la idea de la propiedad privada como derecho natural y acentuando la importancia del principio según el cual los bienes de la creación deben estar al servicio de todos.?

\subsection{El destino universal de los bienes y opción por los pobres}

Curran encara a continuación algunas dificultades de su propio argumento, fundado en la prioridad del destino universal de los

5 Para una posición sustancialmente coincidente pero más matizada del pensamiento de León XIII sobre la propiedad privada, que toma en cuenta otras afirmaciones de RN que compensan en cierto modo su sesgo liberal. por ej., los textos que recuerdan los deberes anejos a su posesión (RN 16), cf. Ildefonso Camacho, Doctrina social de la Iglesia (Madrid: San Pablo, 1991), 76-78.

6 CST 179. Cf. John A. Ryan, Distributive Justice. The Right and Wrong of our Present Distribution of Wealth (New York: MacMillan, 1916), 56-60 (citado por CST, 178). La misma idea del carácter exclusivamente instrumental de la propiedad privada se encuentra en CDS 177 , invocando PP 22-23.

7 CST, $179-181$ 
bienes creados. La formulación de este principio refleja todavía la idea de una economía tradicional prevalentemente agraria, basada en la explotación de los recursos naturales. Pero en la actualidad, la riqueza no depende tanto de los bienes naturales o creados, cuanto de la habilidad, la creatividad, el espíritu de empresa, puestos al servicio de la producción. En otras palabras, cada vez más la verdadera fuente de riqueza es el hombre mismo.

Aun así, este protagonismo humano en la creación de riqueza debe ser entendido a la luz de la solidaridad, que constituye el mejor fundamento para sostener la dimensión social de los bienes exteriores. Porque esa iniciativa y creatividad propias del espíritu humano no se desarrollan ni ejercitan de un modo exclusivamente individual, sino en el contexto de la dependencia respecto de Dios, de los demás y del mundo.

Esta triple solidaridad se expresa de un modo especial en el principio de la opción por los pobres. El mismo cuenta con sólidos fundamentos bíblicos y cristológicos, pero además tiene raíces epistemológicas vinculadas a la teología de la liberación. Ésta cuestiona el paradigma científico moderno de la neutralidad, la objetividad y la imparcialidad, argumentando que las mismas son sólo aparentes, y que el conocimiento humano está inevitablemente ligado a prejuicios. Dios tendría un «prejuicio» (prejudice) y una parcialidad en favor de los pobres, sin que ello impida a quienes adoptan esta perspectiva incorporar otros aspectos de la realidad, así como la básica dignidad y los derechos de todos. ${ }^{8}$ Por eso, no es una opción excluyente sino que, tratando preferencialmente a los más vulnerables, realiza la verdadera imparcialidad y fortalece la solidaridad de todo el cuerpo social. ${ }^{9}$

La «parcialidad» en favor de los más débiles, por su parte, debe tomar la forma de una opción vivida. De ahí que la teología de la liberación proponga como método teológico la «primacía de la

8 Cf. CST, 185.

9 Cf. CST, 186, citando en su apoyo a: William O'Neill, «No Amnesty for Sorrow: The Privilege of the Poor in Christian Social Ethics», Theological Studies 54 (1993): 638-656. 
praxis» en lugar de la visión tradicional que hace preceder la teoría a la acción. El objetivo es lograr un «cambio social» impulsado «de abajo hacia arriba», es decir, que tenga a los mismos pobres como principales protagonistas. Esto marca un fuerte contraste con la DSI, que parte de una perspectiva más teórica y universal, aunque la complementariedad entre ambas es posible. ${ }^{10}$

\subsection{El concepto de Justicia social}

En sentido estricto, la justicia social tiene como objeto formal lo que es debido al bien común de la comunidad humana. ${ }^{11}$ Aunque en el intento de caracterizarla de un modo más específico se abren una multiplicidad de opiniones, en su mayoría los autores la identifican con la justicia legal o general, a lo que algunos agregan la justicia distributiva. Para Curran es claro que la DSI ha fracasado en la formulación de su propia idea de justicia.

El documento de los obispos de Estados Unidos Economic Justice for All (EJA, 1986) ha incorporado al tema una clarificación importante, al caracterizar la justicia social como «justicia contributiva». ${ }^{12}$ Si el término justicia legal suele evocar la mera obligación de obedecer las leyes justas, esta última enfatiza muy bien la importancia del rol activo de los ciudadanos, que deben participar en el logro del bien común o contribuir al mismo.

A continuación, Curran lamenta el ethos americano que se inclina a entender toda justicia en términos de justicia conmutativa, es decir, la que rige entre individuos y grupos particulares, por ejemplo, en los intercambios, según el criterio de igualdad aritmética. Pero este tipo de justicia es «ciega», en el sentido de que no contempla las desigualdades y diferencias entre las personas. Ésta es precisamente la función de la justicia distributiva, que no consiste en una

10 Cf. CST, 186. Es claro que el autor adhiere al liberacionismo.

11 Cf. CST, 189.

12 EJA 71. 
igualdad aritmética sino en una proporcionalidad en la distribución de beneficios y cargas.

En lo que se refiere a los bienes, la justicia distributiva debe seguir ante todo el criterio de la necesidad, fundado en la dignidad de la persona humana y el destino universal de los bienes, para garantizar a todos la posibilidad de una vida digna. El camino ordinario para esta distribución es el del trabajo y la justa remuneración. Pero una vez superado el mínimo básico, entran en juego también otros criterios además de la necesidad -como la igualdad, la productividad y la escasez-, evitando caer en los extremos del individualismo (que sólo considera los méritos individuales) y del colectivismo (que pretende imponer una igualdad absoluta).

Sin embargo, las crecientes diferencias entre ricos y pobres han llevado a la DSI a enfatizar la importancia de la igualdad sobre el mérito. El autor propone que más allá del mínimo básico ya mencionado, se aplique el segundo principio de justicia de John Rawls, según el cual se justifican sólo aquellas desigualdades que redunden en el beneficio de los más pobres. ${ }^{13}$ Sería una manera de hacer efectiva la opción preferencial por los pobres.

Es cierto que las raíces preindustriales de la DSI la han llevado a focalizarse en la distribución de los bienes existentes sin considerar adecuadamente, hasta Juan Pablo II, el fenómeno de la creación de la riqueza a través de la iniciativa económica privada y la creatividad (CA 32). Pero esta aclaración no aporta, para Curran, ninguna novedad significativa a lo ya dicho: tal riqueza también debe ser distribuida, del mismo modo que la ya existente, en base a criterios de solidaridad y justicia distributiva. Sin embargo, el autor hace notar que la perspectiva algo limitada de la distribución de bienes materiales ha sido progresivamente completada con la atención a los bienes espirituales, a través del llamado a la participación de los obreros en la empresa (QA 65) y la prioridad de la dimensión subjetiva del trabajo (LE 8).

13 Cf. J. Rawls, Teoría de la Justicia (México: Fondo de Cultura Económica, 19952), 67-68. 


\subsection{Implicaciones particulares}

La justicia distributiva no se refiere sólo a la distribución de los beneficios, sino también a la de las cargas. Esto lleva al autor a ocuparse de la teoría de la justa imposición. Éste es un tema que no recibe mayor atención en los documentos papales (salvo el criterio de la correspondencia con la capacidad de pago del contribuyente, indicado en Mater et Magistra 132). Pero EJA 202 es más específico, apoyando el principio de progresividad como exigencia indiscutible de la justicia distributiva, es decir, que los que tienen más deberían pagar un porcentaje mayor de sus ingresos. Lamentablemente, afirma, el sistema tributario americano se ha hecho crecientemente regresivo, imponiendo mayores cargas a los bajos ingresos.

En otro orden de cosas, según Curran, EJA «se opone al libre comercio», ${ }_{1}^{14}$ y exhorta a una reducción de la deuda de las naciones pobres.

\subsection{Capitalismo y socialismo}

Finalmente, Curran se ocupa de la cuestión del sistema económico apropiado para realizar los principios de justicia señalados. Hace notar que, mientras RN comienza con una condenación al socialismo y sólo ocasionales críticas al capitalismo, Pío XI ensancha la perspectiva, interpretando RN como una toma de distancia frente a ambos sistemas. Sin embargo, la oposición no es aún simétrica, ya que reconoce que el capitalismo «no es vicioso por su misma naturaleza» (QA 101) mientras que el comunismo es «intrínsecamente perverso» (DR 58).

Con Juan XXIII comienza, sin embargo, una atemperación del anticomunismo, tendencia que continúa Pablo VI como exigencia

14 Curran no da una referencia precisa sobre este punto en el documento. Quizás se refiere a la facultad de regular el comercio, que EJA 123 le reconoce de un modo general al Estado. Pero más bien, sin perjuicio de los reclamos de equidad, el texto señala las ventajas que han obtenido muchas naciones pobres a través del libre comercio, cf. $267 \mathrm{~b}$. 
de su Ostpolitik, destinada a hacer posible la misión de la Iglesia en los países ubicados detrás de la Cortina de Hierro. Este papa dirige fuertes críticas al capitalismo que no tienen correspondencia respecto del marxismo. Incluso, retoma las diferenciaciones de su predecesor entre diferentes sentidos del socialismo (OA 31-34) que, a juicio de Curran, abrirían la puerta para un uso del marxismo como herramienta de análisis sociológico. ${ }^{15}$ De este modo habría corregido la asimetría de las primeras etapas de la DSI.

En cuanto a Juan Pablo II, en el ámbito de la propiedad privada LE 14 sustentaría una perfecta simetría en su rechazo del programa colectivista y el capitalista-liberal. Sin embargo, CA 42 muestra un claro, aunque cualificado, apoyo a la economía de mercado, y afirma la imposibilidad de un compromiso con el marxismo, oponiéndose a la utilización de su método en la teología de la liberación (CA 26). Este pontífice reconoce la importancia del mercado, la propiedad privada, la creatividad, la ganancia y la actividad empresarial, siempre que estén subordinadas al destino universal de los bienes.

\section{2. «Christian Economic Ethics», de Daniel Finn}

En comparación con Curran, D. Finn dedica mayor atención que Curran a la función personal de la propiedad privada,

«Poseer propiedad sobre las cosas aporta una importante dimensión al desarrollo humano, en el sentido de que la persona puede asumir proyectos, fijarse propósitos y cumplirlos. Este sentido de iniciativa personal es una parte importante de la agencia humana y un reflejo de la dignidad humana, participando así del plan creador de Dios para la humanidad».16

Pero, aun así, su mayor atención se concentra en rechazar con insistencia la idea de la propiedad privada como un derecho absoluto, desconectado de su función social.

15 Cf. CST, 203.

16 Daniel K. Finn, Christian Economic Ethics. History and Implications (Minneapolis: Fortress Press), 1984 (en adelante, CEE), 352. 


\subsection{Propiedad privada y ley natural}

Para ello, igual que el autor antes analizado, pone en duda el carácter natural de la propiedad privada, y ve en el magisterio de León XIII y Pío XI sobre el tema «el punto más alto» del individualismo propio del capitalismo de fin de siglo. ${ }^{17}$ En parte, esta posición sería explicable por el hecho de que estos papas veían en el socialismo el culpable del alejamiento de las masas obreras de la Iglesia, fenómeno que en realidad era en mayor medida producto de la disrupción social provocada por la revolución industrial. ${ }^{18}$

Estos pontífices -sostiene Finn coincidiendo con Curran- van más allá de la doctrina tomista al afirmar que la propiedad privada no es una creación humana sino una intención del mismo Creador. ${ }^{19}$ Para S. Tomás, en cambio, la propiedad privada sería una institución creada para afrontar la condición pecadora de la vida humana, ${ }^{20} \mathrm{y}$ dado ese contexto, constituye una prudente «adición» a la ley natural, como la invención del vestido, ${ }^{21}$ una «construcción» que no habría tenido lugar si el hombre hubiera hallado más útil la propiedad común. Este autor parece poner incluso en paralelo la propiedad privada con otra «adición» mencionada por Tomás: la esclavitud. Para el Aquinate, conforme a la intención original de Dios no debería haber esclavos, pero supuesto el pecado original, puede ser adecuado y aun beneficioso que unos estén a cargo de otros. ${ }^{22}$

Según Finn, la idea patrística de que Dios creó el mundo en beneficio de todos y la consiguiente obligación de compartir lo superfluo fue incorporada por S. Tomás en el cuadro de una teoría de la ley natural que no se presta a lecturas individualistas del tipo

17 Daniel Finn, "Commentary on Centesimus annus», en Kenneth Himes, (ed.), Modern Catholic Social Teaching. Commentaries \& interpretations (Washington DC: Georgetown University Press, 2004), 436-466, 444 (en adelante, MCST).

18 En CEE 241, reconoce en cambio la influencia en esa disrupción de la prédica anti-religiosa del socialismo.

19 Cf. CEE, 240.

$20 \mathrm{Cf}$. CEE, 186.

21 Cf. ST II-II, 66, 7

22 Cf. CEE, 150. 
que predominaron en las primeras etapas de la DSI. Partiendo de la distinción ya señalada entre la titularidad de las cosas y su uso, este último no puede ser arbitrario sino que debe estar al servicio de las necesidades de otros, lo cual implica el deber de compartir con el necesitado, e incluso la licitud de que en caso de inminente peligro este último tome de la propiedad del rico por su cuenta.

León XIII habría relegado la importancia que S. Tomás asignó al uso común de los bienes materiales, llevado por una sobreestimación del peligro que representaba el socialismo para la doctrina católica de la propiedad, entendiendo que el marxismo se oponía a toda propiedad privada, cuando en realidad el mismo sólo rechazaba la propiedad privada de los medios de producción industrial: herramientas, máquinas, fábricas. Para León XIII, por lo tanto, la obligación de los propietarios de compartir con los necesitados «es un deber, no de justicia (salvo en casos extremos) sino de caridad cristiana» (RN 19), o según Pío XI, «una grave obligación de caridad, beneficencia y liberalidad» (QA 50), mientras que S. Tomás veía el deber de compartir como un deber de justicia. ${ }^{23}$

Para Finn, Juan XXIII comienza una toma clara de distancia de la visión de los anteriores pontífices, recuperando y desarrollando la tradición tomista. ${ }^{24}$ También Juan Pablo II insiste de un modo enérgico en las obligaciones de los propietarios y la «hipoteca social» que pesa sobre sus posesiones (SRS 42). La propiedad privada de los medios de producción es legítima cuando está al servicio del trabajo (CA 43). ${ }^{25}$

Incluso en el cap. IV de CA, Juan Pablo II pasa del argumento sobre el derecho de propiedad privada al derecho $a$ la propiedad

$23 \mathrm{Cf}$. CEE, 242. Sin embargo, admite Finn que Pío XI critica la idea de reducir los deberes de los ricos a la caridad excluyendo los deberes de justicia (QA 4, cf. CEE, 376).

$24 \mathrm{Cf}$. CEE, 268. Cabe señalar, sin embargo, que Juan XIII elenca el derecho de propiedad entre los derechos naturales, aunque no deja de señalar su función social (PT 21-22; MM 109, 43).

25 Cf. Citando a Juan Pablo II (LE 14), Finn observa que el «destino universal de los bienes» y la idea de la «hipoteca social» sobre la propiedad privada son traducciones contemporáneas de la insistencia tradicional en el «uso común», fundado en la idea de que «los bienes inferiores están al servicio de las necesidades humanas» (ST II-II, 66, 7). 
privada, indicando que no sólo los que poseen propiedad privada tienen derecho a ella, sino que todas las personas tienen el derecho de acceder a la misma al menos en la medida necesaria para su sustento y el de aquellos bajo su responsabilidad. Si bien tal idea no se podría encontrar literalmente en $S$. Tomás, que se enfocaba en el respeto de la naturaleza de los bienes poseídos -o sea, la necesidad de utilizarlos según la voluntad de Dios- nada impide hoy plantear la posición del necesitado en términos modernos de derechos subjetivos, sin por ello dejar de lado el fundamento trascendente de los mismos. ${ }^{26}$

\subsection{Capitalismo y socialismo}

Al mismo tiempo que León XIII y Pío XI eran férreos defensores de la propiedad privada, se mostraban contrarios al liberalismo decimonónico y su idea de maximizar la libertad económica minimizando el control del gobierno sobre la economía. Aquellos veían la raíz de muchos problemas sociales en el individualismo rampante y la afirmación del propio interés en la vida económica, por lo cual -aun oponiéndose a la idea de la planificación centralabogaban por una mayor intervención del Estado en la «estructuración de los mercados». ${ }^{27}$

Aun así, en Pío XI la oposición frontal de León XIII al socialismo (RN 23) se hace más matizada, al reconocer una variante de socialismo que -a diferencia del soviético- aceptaba participar en el sistema democrático (QA 113), aunque siguiera siendo inconciliable con la doctrina católica por su visión secular y anti-religiosa de lo social.

Finn reconoce con claridad la importancia económica del mercado y de la libertad económica, vinculándola a la antropología cristiana, que promueve una sociedad de «individuos fuertes», con espíritu de iniciativa y sentido de responsabilidad por la propia

27 CEE, 243. 
vida. ${ }^{28}$ Sin embargo, citando PP 26 y 59, señala el problema ético que plantean los mercados «mal estructurados», ${ }^{29}$ ya que la justicia económica individual no es suficiente si no se conforma a las demandas de la justicia social. Los mercados necesitan de un encuadre jurídico que garantice una igualdad básica entre los participantes (CV 36). De esta manera, busca un equilibrio entre la perspectiva «liberacionista», que resalta las críticas del magisterio al liberalismo económico pero desconoce su apoyo al mercado y los negocios, y la de los sectores «neoconservadores», que cometen el error opuesto resaltando los textos que apoyan la propiedad privada y el mercado e ignorando las obligaciones de justicia de los propietarios o las condiciones para un capitalismo aceptable. ${ }^{30}$

Como modo de superar este enfrentamiento, Finn propone considerar cuatro cuestiones que son fundamentales a los efectos de brindar una «ecología moral» a los mercados. Sólo aquellas visiones que puedan dar respuesta a dichos requisitos básicos pueden considerarse en continuidad con la enseñanza de la Iglesia. Estos problemas son: (1) la asignación de recursos; (2) la distribución; (3) la producción en escala; y (4) la cualidad de las relaciones interpersonales. Los mercados cumplen una función importante en cuanto a la eficiencia, innovación e inversión (1), e incluso fomentan diversas virtudes comerciales (4). Pero también comportan dificultades inevitables, como la destrucción creativa y sus costos humanos inmediatos; no solucionan algunos problemas distributivos que afectan a los más pobres (2), ni tampoco son aptos para determinar la escala de una economía compatible con las posibilidades de la biosfera (3). Estos límites delinean el ámbito en que es requerida la intervención estatal. 


\subsection{Justicia social e implicancias particulares}

Con un enfoque similar al de Ch. Curran, señala Finn que la justicia social es aquella que articula las obligaciones del individuo para contribuir al bien común de la comunidad, con las obligaciones de la comunidad para hacer posible al individuo dicha contribución. ${ }^{31}$ En lo político, esto implica el derecho de todos los ciudadanos de participar en la vida pública, y en lo económico, una colaboración del sector privado y del Estado para asegurar suficientes oportunidades de trabajo adecuadamente remuneradas.

La obligación moral de los propietarios hacia los necesitados, señalada enfáticamente por $S$. Tomás, es la base para justificar los impuestos a las personas acomodadas para financiar servicios básicos en favor de los más pobres. ${ }^{32}$ Finn rechaza como infundado el temor de que esta política tributaria debilite el sentido personal de solidaridad o que redunde en perjuicio de la creación de puestos de trabajo. ${ }^{33} \mathrm{Y}$ al igual que Curran, aboga por los impuestos progresivos, entendidos como una consecuencia de la idea de justicia social, pues la progresividad garantiza una «igualdad en sacrificio», cuando los ricos pagan proporcionalmente más que la clase media o los pobres. ${ }^{34}$

Finn sostiene la bondad del comercio internacional, aunque éste debe estar sometido a reglas. ${ }^{35}$ Por un lado, es un beneficio para la sociedad, permitiendo a los consumidores pagar precios más bajos por una amplia variedad de bienes; por el otro, puede perjudicar a productores locales. Se requiere que una porción de los impuestos sea dedicada a la asistencia en orden a la reubicación de los trabajadores de los sectores afectados. 


\section{3. «Option for the Poor and for the Earth», de Donal Dorr}

En su obra Option for the Poor and for the Earth, ${ }^{36}$ Donal Dorr adopta una perspectiva más interesada en restringir el alcance del derecho de propiedad privada con fines distributivos que de comprender su función en la vida económica y social.

\subsection{Propiedad privada y su función social}

Siguiendo a M.-D. Chenu y a R. Laurentin, recuerda Dorr que el temor al socialismo llevó a León XIII a modificar el borrador de RN en que se mencionaba explícitamente la subordinación de la propiedad privada al principio de que los bienes de la tierra están ordenados al bien común, apartándose de ese modo de la auténtica doctrina tomista. ${ }^{37}$ Avala de este modo la tesis de $\mathrm{Ch}$. Curran según la cual esta absolutización de la propiedad privada estaba fundada en el temor de que la limitación de este derecho pudiera tener consecuencias desestabilizadoras y revolucionarias, así como en la incapacidad de diferenciar entre diferentes corrientes del pensamiento de izquierda, lo que llevaba a una exagerada polarización. ${ }^{38}$

Pío XII sería quien más claramente corrigió el sesgo de RN en esta materia, afirmando la subordinación de la propiedad privada al uso común de los bienes de la tierra. ${ }^{39}$ Sin embargo, sobre todo en la segunda parte de su pontificado, Pío XII aceptó como «opción práctica» la sociedad capitalista, motivado por el «realismo» (el reconocimiento de que ésta había evolucionado y había realizado avances en la lucha contra la pobreza) y el temor a las

36 Donal Dorr, Option for the Poor and for the Earth. Catholic Social Teaching (New York: Orbis Books, Ed. Kindle, 2012), en adelante, OPE.

37 Cf. OPE, pos. 844; cf. Marie - D. Chenu, La "doctrine sociale" de l'Église comme idéologie, Paris, Cerf, 1979, 22; René Laurentin, Liberation, Development and Salvation, Maryknoll, NY, Orbis Books, 1972, 96-97.

38 Cf. OPE, pos. 848; Curran, CST, 177-178.

39 Cf. OPE, pos. 1602; Pío XII, D3, 198-199. 
tendencias socialistas canalizadas en el nuevo Estado del bienestar. Esta postura, sostiene Dorr, hizo posible que la DSI sobre la propiedad fuera utilizada ideológicamente por la derecha, sobre todo en Latinoamérica, para oponerse a la reforma agraria y a una más equitativa distribución de la riqueza. ${ }^{40}$ Esto justificaría el "giro a la izquierda» de Juan XXIII, con su insistencia en las obligaciones sociales inherentes a la propiedad privada, que abre el camino para una opción por los pobres en los siguientes pontífices. ${ }^{41}$ Juan Pablo II sería la expresión madura de este cambio de énfasis, el paso de la preocupación por la propiedad privada a la preocupación por la pobreza. ${ }^{42}$

\title{
3.2. Economía de mercado y socialismo
}

En su posicionamiento claramente cercano al socialismo, Dorr procura sortear la dificultad que le plantea Juan Pablo II en CA 42. En este número, el mencionado pontífice responde a la pregunta sobre el capitalismo con una célebre distinción:

\begin{abstract}
"Si por "capitalismo" se entiende un sistema económico que reconoce el papel fundamental y positivo de la empresa, del mercado, de la propiedad privada y de la consiguiente responsabilidad para con los medios de producción, de la libre creatividad humana en el sector de la economía, la respuesta ciertamente es positiva, aunque quizá sería más apropiado hablar de "economía de empresa", "economía de mercado", o simplemente de "economía libre". Pero si por "capitalismo" se entiende un sistema en el cual la libertad, en el ámbito económico, no está encuadrada en un sólido contexto jurídico que la ponga al servicio de la libertad humana integral y la considere como una particular dimensión de la misma, cuyo centro es ético y religioso, entonces la respuesta es absolutamente negativa».
\end{abstract}

En la interpretación de Dorr, esta distinción entre dos significados de la palabra capitalismo consiste en rechazar el capitalismo en la medida en que significa liberalismo económico y aceptarlo sólo 
en el sentido de permitir a las personas asumir iniciativas económicas. ${ }^{43}$ Para este autor, al parecer, el capitalismo liberal está privado por definición de «un sólido contexto jurídico» y es incompatible con una dimensión ética y religiosa. Esto le permite negar al texto citado cualquier viso de novedad:

«En lo que respecta al capitalismo, la posición de Juan Pablo está muy en línea con la tradición de la enseñanza social establecida por la Iglesia a lo largo de los cien años previos: favorece en buena medida la libre empresa pero no está satisfecho con la ideología del capitalismo liberal». ${ }^{44}$

Y continúa un poco más adelante:

"Debemos concluir, entonces, que al optar por la "economía de mercado", Juan Pablo no está realmente dando su aprobación al capitalismo como el sistema correcto. Está simplemente estableciendo ciertas condiciones mínimas para cualquier modelo de sociedad aceptable, a saber, que el derecho de poseer, comprar y vender bienes, y el derecho de tomar otras iniciativas económicas, aunque pueden requerir de control, no deben ser totalmente abolidos». ${ }^{45}$

La «respuesta ciertamente positiva» del texto pontificio a la economía de empresa queda reducida a un mero «no rechazo». Nótese además que el control del Estado parece aceptable en la medida en que la libertad económica no que totalmente abolida. De todo lo cual, concluye:

«En línea con la tradición de sus predecesores, y especialmente las encíclicas de León XIII y Pío XI, Juan Pablo concluye que ni el capitalismo liberal ni el comunismo alcanzan el mínimo de condiciones requeridas en orden a que un sistema económico pueda ser moralmente aceptable». 


\subsection{Conclusiones}

Hemos presentado brevemente la doctrina de tres autores sobre la propiedad privada, ubicándola en el contexto más amplio de su respectiva visión de los sistemas sociales. Es claro que hay importantes matices entre ellos. Daniel Finn, especialista en ética económica, muestra una mejor comprensión y aprecio de la función del mercado en la economía. Charles Curran tiene al respecto una actitud más recelosa, aunque reconoce -al menos de un modo genérico y fuertemente condicionado- el valor de la libertad económica. Donal Dorr, por su parte, adopta una posición muy cercana al socialismo. Estas diferencias repercuten en su visión de la propiedad privada, pero dejando en pie un amplio margen de acuerdo.

En los tres autores encontramos el mismo argumento básico. La propiedad privada está subordinada al destino universal de los bienes, los cuales han sido creados por Dios para el uso de todos los hombres. Más aún, aquélla no es de derecho natural en sentido propio, sino que surge como un «agregado», fruto del descubrimiento racional de su conveniencia práctica, en la situación posterior al pecado original. De aquí se sigue que esta institución se justifica ante todo por su dimensión social, respecto de la cual este derecho posee un rol mayormente -cuando no exclusivamente- instrumental.

Al ser establecido este derecho por ley humana y revestir un carácter convencional, el Estado tiene competencia para poner límites no sólo a su uso sino incluso a su titularidad, a través de su potestad redistributiva según el criterio de la justicia social. De este modo es posible justificar (sin que ello implique necesariamente el rechazo del mercado) diversas políticas de intervención en la vida económica, como el establecimiento de impuestos progresivos y diversos límites reglamentarios (no identificados claramente) a este derecho y a su ejercicio. Tanto León XIII como Pío XI, influidos por el individualismo de la época, habrían acordado al derecho de propiedad un carácter absoluto ajeno a la tradición eclesial precedente, sesgo que la DSI posterior habría corregido acentuando la «hipoteca social» que pesa sobre dicho derecho. 
En la última parte de este artículo, quisiera hacer una apreciación crítica de estas afirmaciones.

\section{La propiedad privada y la ley natural}

El punto de partida de esta visión compartida de la propiedad privada es la afirmación de que, según Santo Tomás, la misma no es de derecho natural sino de ley positiva, a partir de la cual se considera la posición de León XIII y de Pío XI un apartamiento de la tradición precedente. Tal afirmación, sin embargo, constituye una verdad a medias, formulada con imprecisión, y merece por consiguiente un análisis detenido.

\subsection{Propiedad privada y razón natural}

Como enseña ST II-II, q.57, a.3, algo puede pertenecer a «lo justo natural» de dos maneras:

1) considerando la cosa «absolutamente y en sí misma»; de este modo, el ser masculino se adecúa, por su naturaleza, al ser femenino para engendrar de éste, y los padres, al hijo, para nutrirlo;

2) considerando la cosa «no absolutamente, en su naturaleza, sino en relación a sus consecuencias»; por ejemplo, la propiedad de las posesiones. Y acá explica ya S. Tomás lo que luego desarrollará luego en la q.66:

«En efecto, si este terreno se considera en absoluto, no tiene por qué ser más de éste que de aquél; pero, si se considera en cuanto a la aptitud de ser cultivado y al pacífico uso del campo, tiene, según esto, cierta disposición para que sea uno y no otro».

Ahora bien, la primera consideración es propia de «lo natural» como común a hombres y animales. La segunda, en cambio, es la propia del «derecho de gentes» privativo de los hombres, ya que considerar algo en comparación con lo que de ello se deriva (las 
consecuencias) es propio de la razón; y de aquí que esto, ciertamente, sea natural al hombre, debido a que es la razón natural la que lo dicta. Sólo en el primer sentido considera el Aquinate que la propiedad privada no es de ley natural sino un agregado de la razón humana para utilidad del hombre.

Curran interpreta los dos artículos de la Suma dedicados específicamente a la propiedad (II-II, q.66, aa.1-2) como referidos, el primero, a la propiedad común y el segundo, a la propiedad privada. Considerados conjuntamente, serían una afirmación del carácter natural de la propiedad común (a.1) en contraste con el carácter convencional y subordinado de la propiedad privada (a.2). En realidad, esta suposición es discutible. El art. 1 se refiere a la propiedad de un modo general (sin tener presente su carácter común o privado) y analiza su correspondencia con la naturaleza humana. En este sentido, la propiedad de cosas exteriores (de modo común o exclusivo) deriva del carácter racional del ser humano como imagen de Dios (art.1, c.), teniendo presente sin embargo que, en cuanto a su naturaleza, el dominio de las cosas exteriores pertenece siempre a Dios.

Nada encontramos entonces en ese primer artículo que induzca a pensar que se esté hablando específicamente de la propiedad o el uso común. Esto es confirmado por el art.2 ad 1:

«La comunidad de los bienes se atribuye al derecho natural, no porque éste disponga que todas las cosas deban ser poseídas en común y que nada deba poseerse como propio, sino porque la distinción de posesiones no es según el derecho natural, sino según la convención humana, lo cual pertenece al derecho positivo).

El derecho natural no dispone que las cosas sean poseídas en común más que en particular. Pero obviamente la "distinción de posesiones" (no el derecho en sí) requiere de normas positivas que asignen o reconozcan su titularidad y la garanticen.

En síntesis, el texto de 1a q.66, a.1 se refiere al fundamento antropológico del derecho del hombre a poseer bienes exteriores sea en común o como algo propio. Recién en q.66, a.2 aborda el 
problema de la modalidad de esa posesión. Ciertamente, las razones que enumera en favor de la propiedad privada son de orden práctico, y están fundadas en la consideración de las consecuencias (cf. II-II, q.57, a.3). Pero ello no significa que dichas razones sean irrelevantes desde el punto de vista moral, y puedan considerarse meramente "pragmáticas», porque son una concreción del fundamento antropológico (la naturaleza humana racional) señalado en el artículo precedente. Y por esto mismo no puede afirmarse, como hace Curran, que se trate necesariamente de consecuencias del pecado original. No parece que la necesidad de ordenar la gestión de los bienes y de clarificar el alcance de los respectivos derechos sea la consecuencia de la pecaminosidad humana, es decir, del egoísmo, aunque sí puedan serlo las reacciones motivadas por las dificultades que dichas tareas conllevan.

\subsection{Propiedad privada y pecado original}

Es cierto que I, q.98, a.1 ad 3 considera la propiedad privada como resultado del pecado original, y que con ello sigue una tradición que se hizo común entre canonistas y escolásticos. Pero se debe tener en cuenta que en este artículo se está hablando de un problema muy distinto: si en el estado de inocencia habría habido generación. Para responder afirmativamente sin conceder que la multiplicación de los hombres hubiera hecho necesaria en el estado original la propiedad privada (contra la autoridad de S. Isidoro), argumenta que: «en el estado de inocencia estaban de tal modo armonizadas las voluntades de los hombres, que cada uno hubiese tomado del bien común lo que le correspondía sin peligro alguno de discordia», como se puede ver ahora entre «hombres honestos». Nuevamente, esta ausencia de discordia depende de la posibilidad de saber con certeza lo que le corresponde a cada uno, lo cual no podría darse siempre de modo enteramente espontáneo, más allá de la generosidad o del egoísmo de los miembros de tal comunidad. 
La vinculación con el pecado original es, entonces, una afirmación incidental que Tomás no repite cuando trata específicamente de la propiedad privada y alude a necesidades que no dependen necesariamente de la honestidad de las personas. Como observa acertadamente C. Kossel, lo que no es natural es la división de las propiedades, no el derecho mismo:

«El segundo texto (II-II, q.66, a.2), el texto temático de Tomás sobre la propiedad privada, argumenta que la posesión privada (potestas procurandi et dispensandi) es lícita y necesaria para la vida social humana. Por derecho natural (ius naturale) todas las cosas son comunes sólo en el sentido de que la naturaleza no ha dividido las cosas ni las ha designado para personas particulares; la actual división de la sociedad sucede por acuerdo humano y en ese sentido pertenece al ius positivum (ad 1)». ${ }^{46}$

Es preciso tener presente además que, como señala Tierney, entre canonistas y teólogos medievales existían teorías muy diferentes sobre el estado de inocencia original y el origen de la propiedad privada. Para Rufino, en dicho estado anterior a la caída, la posesión común era de ley natural no en el sentido de que constituyera un precepto sino simplemente una «demostración», una situación de hecho que podía ser alterada por la ley. ${ }^{47}$ Huguccio, por su parte, sostenía que la propiedad común era un verdadero precepto permanente de la ley natural, pero sólo en el sentido de que el uso de dichos bienes por sus propietarios debía ser compartido con otros en caso de necesidad. En cualquier caso, veían la ley natural ante todo como ley de la razón, y el primitivo comunismo que imaginaban era un punto de partida histórico y no un ideal al que hubiera que volver. ${ }^{48}$ La referencia al pecado original, por lo tanto, no es de gran ayuda al momento de pensar los alcances y límites de la propiedad privada.

46 Clifford G. Kossel, S.J., "Thomistic Moral Philosophy in the Twentieth Century", en Stephen J. Pope (ed.), The Ethics of Aquinas (Washington, DC: Georgetown University Press, 2002), 385-411, 397 n.11

47 Brian Tierney, The Idea of Natural Rights. Studies on Natural Rights, Natural Law and Church Law (Grand Rapids, Michigan) - Cambridge, UK: Eerdmans, 2001), 138.

48 lbid. 139 
Como sea, para Santo Tomás la propiedad privada es un caso típico del derecho de gentes (II-II, q.57, a.3), que tanto para aquél como para los juristas romanos era un derecho natural, es decir, que se impone por su misma naturaleza y no por alguna institución o voluntad humana. ${ }^{49} \mathrm{El}$ derecho de gentes «son normas que la razón humana deriva por deducción necesaria de los mismos principios de derecho natural, y comprende, por lo tanto, todas las conclusiones - primeras, secundarias y más remotas- que se infieren de esos principios». ${ }^{50}$ Es, por lo tanto, un derecho anterior y superior al Estado, que no emana del derecho positivo.

\section{El destino universal de los bienes y la «hipoteca social» de la propiedad}

Siendo parte del derecho de gentes, la propiedad privada es un derecho natural secundario, es decir, deducido por la razón natural considerando las necesidades prácticas y universales de la realidad social. Por consiguiente, debe ceder al «orden natural instituido por la divina providencia» según el cual «las cosas inferiores están ordenadas a la satisfacción de las necesidades de los hombres», de modo que «por la distribución y apropiación, que procede del derecho humano, no se ha de impedir que con esas mismas cosas se atienda a la necesidad del hombre». ${ }^{51}$

Como derecho natural secundario, no puede considerarse absoluto, sino que está subordinado al destino universal de los bienes. Curran observa con acierto que este principio ha sido formulado teniendo en vista una sociedad pre-industrial y, por lo tanto, tomando en cuenta los bienes ya existentes en la naturaleza. En la economía moderna, sin embargo, la riqueza reside no tanto en los recursos na-

49 Cf. Santiago Ramírez, «Introducción a la cuestión II-II q. 66», en Suma Teológica, VIII, (Madrid: BAC, 1956), 483.

50 Sólo en el s. XVI comienza a considerarse el derecho de gentes como derecho fundamentalmente positivo, de carácter consuetudinario, establecido por todas las gentes.

51 ST, II-II, q.66, a.7. 
turales y los bienes acumulados, cuanto en la creatividad y la iniciativa, en la innovación y el desarrollo tecnológico. Pero este autor no extrae las implicancias de este hecho: más decisivo que la distribución de bienes materiales es capacitar a las personas para acceder a estas nuevas creaciones del ingenio humano y el correspondiente knowhow, lo que reclama iniciativas a nivel nacional e internacional para hacer de dichos bienes patrimonio común de la humanidad y brindar a los pueblos más pobres la posibilidad de desarrollo (CA 35). Estas mismas consideraciones muestran lo inadecuado del planteo que insiste en la limitación de la propiedad privada como única manera de hacer efectivo el destino universal de los bienes.

Es verdad que la tradición cristiana nunca ha considerado la propiedad privada como algo absoluto e intocable (CDS 177) y que sobre la misma pesa una función social o «hipoteca social», ${ }^{2}$ que comporta límites en el uso de los bienes por parte de los legítimos propietarios (por ej., no tener inoperantes los bienes poseídos, y destinarlos a la actividad productiva, CDS 178). En concreto, los «bienes superfluos» son debidos por derecho natural al sostenimiento de los pobres. Pero habitualmente «se deja al arbitrio de cada uno la distribución de las cosas propias para socorrer a los que padecen necesidad». Sólo cuando ésta es extrema, no sólo la persona afectada, sino incluso un tercero está habilitado para «tomar clandestinamente la cosa ajena para socorrer así al prójimo indigente» (II-II, q.66, a.7, ad 3). Pero salvo en este último caso, no se trata de un deber de justicia que pueda ser exigido por ley sino de «caridad cristiana» (RN 16). ${ }^{53}$

Por su parte, es importante aclarar, lo «necesario» (en función de lo cual se concreta el concepto de lo «superfluo») debe ser entendido como aquello “sin lo que no se puede vivir a tenor de las exigencias normales de la condición y del estado de la propia persona y de los demás cuyo cuidado le incumbe" (II-II, q.32, a.6, c.).

52 Juan Pablo II, Discurso inaugural de Puebla, III, 28 de enero de 1979

53 "(...) un derecho general de esa especie (de justicia) de "los pobres" sobre lo superfluo de "los ricos" es inactuable por indeterminado y socialmente caótico», cf. José M. Ibánez Langlois, Doctrina Social de la Iglesia (Santiago de Chile: Editorial Universidad Católica de Chile, 19882), 181. 
Estas puntualizaciones son relevantes porque la invocación de la función social de la propiedad tal como la encontramos en los autores citados, no va acompañada por una clara delimitación de las facultades del Estado a ese respecto. Salvo en el caso de situaciones extremas que pongan en riesgo la supervivencia, debe considerarse una violación del derecho a la propiedad privada la sustracción coactiva por parte del Estado de parte de la propiedad de sus ciudadanos para luego distribuirla a otros conciudadanos. ${ }^{54} \mathrm{Al}$ hablar de la "función social de la propiedad" es necesario insistir, por lo tanto, en la distinción entre el deber moral y el deber estrictamente jurídico. Como afirma M. Rhonheimer:

«La hipoteca social de la propiedad implica una obligación moral de cada ciudadano que, en la doctrina social católica clásica, no concede al Estado el derecho de quitar a otros ciudadanos su propiedad en nombre de la "justicia social" empleando su poder coercitivo, tampoco en el caso de que esa confiscación esté legitimada democráticamente por una mayoría». ${ }^{55}$

Sin una distinción adecuada entre el ámbito de la justicia y el de la caridad $-\mathrm{y}$, por lo tanto, entre la función del Estado y la de la Iglesia- se cae fatalmente en el error de considerar exigible, a través del poder coactivo del Estado, lo que es propio de la caridad, lo cual constituye un peligro para la libertad individual, que precisamente la propiedad privada debería garantizar.

En una economía moderna, existe un modo para poner la propiedad privada al servicio de todos que es más efectivo que el de la limosna o el de la redistribución coactiva: la inversión de la misma como capital, a fin de hacer posible la innovación tecnológica, el aumento de la productividad, el trabajo cada vez mejor remunerado, y la mejora generalizada del nivel de vida. En este sentido, se ha

54 Sostenida por figuras relevantes del catolicismo social, como el obispo W. von Ketteler, cf. Martin Rhonheimer, Libertad económica, capitalismo y ética cristiana. Ensayos para un encuentro entre economía de mercado y pensamiento cristiano (Madrid: Unión Editorial, 2017), 97.

55 lbid., 98. 
caracterizado la economía de mercado como «la forma económica del dar». ${ }^{56}$ Como afirma CDS 178:

«El destino universal de los bienes comporta vínculos sobre su uso por parte de los legítimos propietarios. El individuo no puede obrar prescindiendo de los efectos del uso de los propios recursos, sino que debe actuar en modo que persiga, además de las ventajas personales y familiares, también el bien común. De ahí deriva el deber por parte de los propietarios de no tener inoperantes los bienes poseídos y de destinarlos a la actividad productiva, confiándolos incluso a quien tiene el deseo y la capacidad de hacerlos producir».

Teniendo en cuenta una recta comprensión de su función social, la propiedad privada, si bien no constituye un fin en sí misma, tampoco puede ser considerada como un mero instrumento. En contraste con la visión de J. A. Ryan seguida por Ch. Curran, sostiene G. Crepaldi la dignidad propia y originaria del derecho de propiedad privada, que es ocultado por la ideología,

«(...) cuando es contrapuesto al principio del destino universal de los bienes, o cuando es entendido como un instrumento en referencia al mismo, carente de una dignidad propia a no ser como simple medio para realizar la destinación universal. Los dos principios de la propiedad privada y del destino universal de los bienes deben ser entendidos como ubicados en el mismo nivel, me atrevería a decir, como dos caras de un mismo principio. Es cierto que la propiedad privada es la principal vía para realizar el destino universal de los bienes, pero eso no significa de deba ser entendida sólo como un instrumento de dignidad no originaria sino derivada. El mismo, en efecto, está presente incluso en el Decálogo, es un elemento del derecho natural y revelado». ${ }^{57}$

En realidad, se podría decir que la función social de la propiedad está enraizada ante todo en su función personal, y que ambas dimensiones deben concebirse como íntimamente unidas, y no en una

56 Martin Rhonheimer, «El malvado capitalismo. La forma económica del dar», en id., Libertad económica, 37. La idea pertenece a George Gilder en su obra Wealth and Poverty (1981). "Sobre esa base -comenta Rhonheimer-cabría edificar en verdad una ética cristiana de la hipoteca social de la propiedad privada: una oportunidad que hasta ahora apenas se ha aprovechado», cf. M. Rhonheimer, Ibid., 107, nota 51.

57 Mons. Giampaolo Crepaldi, «Liberare l'economia dalle ideologie: un pressante invito della Dottrina Sociale della Chiesa», Lectio magistralis, III Giornata Nazione della Dottrina sociale della Chiesa, Convento francescano di San Daniele, Lonigo (Vicenza,) sabato 17 ottobre 2020, https:// www.vanthuanobservatory.org/ita/giornata-nazionale-della-dsc-la-lectio-del-vescovo-crepaldi-attenti-alle-ideologie/ (consulta: 23-10-20) 
relación de mutua exclusión. Por eso, Juan XXIII, respondiendo a las dudas sobre el principio de propiedad privada, afirma en MM 108:

«...el derecho de propiedad privada, aún en lo tocante a bienes de producción, tiene un valor permanente, ya que es un derecho contenido en la misma naturaleza, la cual nos enseña la prioridad del hombre individual sobre la sociedad civil, $y$, por consiguiente, la necesaria subordinación teológica de la sociedad civil al hombre.

Por otra parte, en vano se reconocería al ciudadano el derecho de actuar con libertad en el campo económico si no le fuese dada al mismo tiempo la facultad de elegir y emplear libremente las cosas indispensables para el ejercicio de dicho derecho.

Además, la historia y la experiencia demuestran que en los regímenes políticos que no reconocen a los particulares la propiedad, incluida la de los bienes de producción, se viola o suprime totalmente el ejercicio de la libertad humana en las cosas más fundamentales, lo cual demuestra con evidencia que el ejercicio de la libertad tiene su garantía y al mismo tiempo su estímulo en el derecho de propiedad».

\section{Capitalismo y socialismo}

Finalmente, por lo dicho con anterioridad se comprende que, si se quiere evitar la manipulación ideológica de la idea de la función social de la propiedad, es preciso una reflexión clara sobre las prerrogativas y límites del Estado en esta materia. Los autores expuestos parecen acordar al Estado una presunción favorable en cuanto a que en principio sus intervenciones serían a favor del bien común. Esta confianza no encuentra suficiente apoyo en la realidad, en la que sobreabundan ejemplos en contrario, por ejemplo, en la forma de una voracidad fiscal que parasita la actividad productiva, y sustrae de ella recursos que llegan escasamente a los supuestos beneficiarios de la redistribución.

Esta confianza ingenua en el Estado -probablemente un resabio de la función «paternal» que le asignaba el magisterio social preconciliar- los lleva a apoyar una supuesta «simetría» de la DSI ante el capitalismo y el socialismo, que no encuentra suficiente apoyo en los documentos de la DSI. Al respecto, Pío XI no podía ser más claro: 
«León XIII puso todo su empeño en ajustar este tipo de economía a las normas del recto orden, de lo que se deduce que tal economía no es condenable por sí misma. Y realmente no es viciosa por naturaleza, sino que viola el recto orden sólo cuando el capital abusa de los obreros y de la clase proletaria con la finalidad y de tal forma que los negocios e incluso toda la economía se plieguen a su exclusiva voluntad y provecho, sin tener en cuenta para nada ni la dignidad humana de los trabajadores, ni el carácter social de la economía, ni aun siquiera la misma justicia social y bien común». (QA 101, subrayado nuestro)

Es cierto que el «giro a la izquierda» de Juan XXIII y Pablo VI hicieron menos clara la asimetría entre ambos sistemas, pero la misma nunca quedó completamente desdibujada, ya que ambos pontífices limitaron sus propuestas prácticas a la reforma del sistema económico, siguieron defendiendo la subsidiaridad y apoyaron el sistema político republicano, posturas incompatibles con la centralización económica y política propia del socialismo. Juan Pablo II, finalmente, proclamó una adhesión explícita a la economía de mercado (CA 42).

Cuando Dorr ve en ese texto una condena al capitalismo «liberal» (que por otro lado hoy prácticamente ha sido sustituido en todo el mundo por un capitalismo de tipo reglamentario), está interpretando dicho pasaje a la luz de presupuestos que le son ajenos. El capitalismo carente de un «sólido fundamento jurídico» no es el capitalismo liberal sino más bien el capitalismo «de amigos» o prebendario (crony capitalism) generado por la colusión entre empresarios y políticos corruptos, es decir, un capitalismo sin reglas. No se condena como tal un sistema, sino la corrupción del mismo. Esta interpretación se ve reforzada por la condena al Estado asistencial (CA 48), y la sobria enumeración de las funciones propias e irrenunciables a las cuales debe atenerse el Estado (ibid.). Con esta visión, Juan Pablo II introduce una sana cautela frente al poder político, muchas veces ausente en el magisterio precedente.

En relación con el rol del Estado es posible cuestionar, finalmente, la idea de los impuestos «progresivos», que para los autores mencionados constituye una consecuencia directa de la idea de justicia social. Como observa Th. Sowell, los impuestos progresivos no 
son impuestos a la riqueza, sino a los ingresos, por lo cual la mayoría de las personas alcanzadas por aquellos no son "ricos", sino simplemente personas que han alcanzado el pico de sus ingresos, quizás después de décadas de trabajo con salarios mucho menores. A ello debe sumarse la inflación, que aumenta el salario nominal sin mejorar el nivel de vida, y puede hacer caer bajo este tipo de leyes a personas cuyo nivel de ingresos no justifican la progresividad. ${ }^{58}$

\section{Conclusión}

La reflexión precedente muestra cuán necesario es hoy volver a reflexionar sobre la doctrina de la propiedad privada y depurarla de sus acrecencias ideológicas. Las mismas se acumulan en buena medida por la concepción meramente instrumental de la subordinación de la propiedad privada al destino universal de los bienes, que desconoce su importancia propia y originaria, e insiste unilateralmente en su función social, concebida de un modo genérico y no encuadrada en una adecuada doctrina del Estado. Esta deficiencia amenaza la continuidad de la enseñanza social de la Iglesia, y constituye un peligro sobre todo para países como la Argentina, donde el Estado, a lo largo de décadas, ha erosionado el derecho de propiedad privada, generando inseguridad jurídica, desconfianza social y destrucción de estímulos económicos.

Como afirma CDS 176:

«Mediante el trabajo, el hombre, usando su inteligencia, logra dominar la tierra y hacerla su digna morada: "De este modo se apropia una parte de la tierra, la que se ha conquistado con su trabajo: he ahí el origen de la propiedad individual" (CA 31). La propiedad privada y las otras formas de dominio privado de los bienes "aseguran a cada cual una zona absolutamente necesaria para la autonomía personal y familiar y deben ser considerados como ampliación de la libertad humana (...) al estimular el ejercicio de la tarea y de la responsabilidad, constituyen una de las condiciones de las liber-

58 Cf. Thomas Sowell, Basic Economics. A Common Sense Guide to the Economy (New York: Basic Books, Ed. Kindle, 20155), 429-431. 
tades civiles" (GS 71). La propiedad privada es un elemento esencial de una política económica auténticamente social y democrática y es garantía de un recto orden social. La doctrina social postula que la propiedad de los bienes sea accesible a todos por igual (CA 6), de manera que todos se conviertan, al menos en cierta medida, en propietarios, y excluye el recurso a formas de "posesión indivisa para todos" (RN 11)».

\section{Bibliografía}

Camacho, Ildefonso. Doctrina social de la Iglesia. Madrid: San Pablo, 1991

Crepaldi, Mons. Giampaolo. Lectio magistralis «Liberare l'economia dalle ideologie: un pressante invito della Dottrina Sociale della Chiesa». Giornata Nazione della Dottrina sociale della Chiesa, Convento francescano di San Daniele, Lonigo (Vicenza) sabato 17 ottobre 2020. Acceso el 23 de octubre de 2020.

https:/ / www.vanthuanobservatory.org/ita/giornata-nazionale-della-dsc-la-lectio-del-vescovo-crepaldi-attenti-alle-ideologie/

Curran, Charles. Catholic Social Teaching (1891-present). A Historical, Theological and Ethical Analysis. Washington DC: Georgetown University Press, 2002

Dorr, Donal. Option for the Poor and for the Earth. Catholic Social Teaching. New York: Orbis Books, Ed. Kindle, 2012

Finn, Daniel K. «Commentary on Centesimus annus». En Modern Catholic Social Teaching. Commentaries \& interpretations, ed. Kenneth Himes. Washington DC: Georgetown University Press, 2004, 436-466

Finn, Daniel K. Christian Economic Ethics. History and Implications. Minneapolis: Fortress Press, 1984

Juan Pablo II, Discurso inaugural de de la III Conferencia General del Episcopado Latinoamericano. Puebla, 28 de enero de 1979. Acceso el 23 de octubre de 2020.

http://www.vatican.va/content/john-paul-ii/es/speeches/1979/ january/documents/hf_jp-ii_spe_19790128_messico-puebla-episc-latam.html 
Kossel, Clifford G. S.J. «Thomistic Moral Philosophy in the Twentieth Century». En The Ethics of Aquinas, ed. Stephen J. Pope. Washington, DC: Georgetown University Press, 2002, 385-411

Pontificio Consejo «Justicia y Paz». Compendio de la Doctrina Social de la Iglesia. Vaticano: Libreria Editrice Vaticana, 2005. Acceso el 23 de octubre de 2020.

http://www.vatican.va/roman_curia/pontifical_councils/justpeace/documents/rc_pc_justpeace_doc_20060526_compendio-dott-soc_sp.html

Ramírez, Santiago. «Introducción a la cuestión II-II q. 66». En Suma Teológica, VIII. Madrid: BAC, 1956

Rawls, John. Teoría de la Justicia. México: Fondo de Cultura Económica, $1995^{2}$

Rhonheimer, Martin. Libertad económica, capitalismo y ética cristiana. Ensayos para un encuentro entre economía de mercado y pensamiento cristiano. Madrid: Unión Editorial, 2017

Rhonheimer, Martin. «El malvado capitalismo. La forma económica del dar». En Ibid., 37

Sowell, Thomas. Basic Economics. A Common Sense Guide to the Economy. New York: Basic Books, Ed. Kindle, $2015^{5}$

Tierney, Brian. The Idea of Natural Rights. Studies on Natural Rights, Natural Law and Church Law. Grand Rapids, Michigan - Cambridge, UK: Eerdmans, 2001 